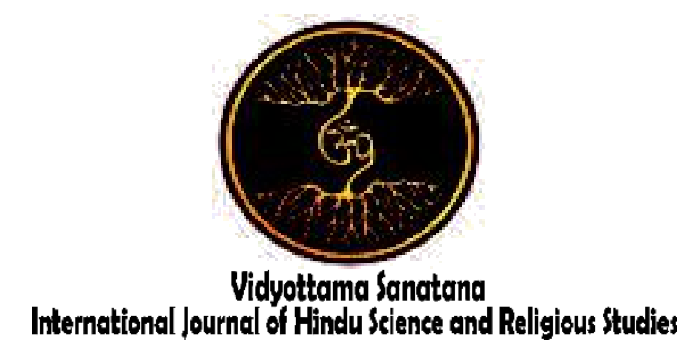

Vol. 4 No. 1 May 2020

\title{
YOGA ASANAS AND INCREASED THE MENTAL ATTITUDE ADOLESCENTS
}

\author{
By:
}

Anando Abioye

South African Yoga Consciousness Institute

E-mail : a.abioye@gmail.com

Received: April 23, 2020

Accepted: May 21, 2020

Published: May 30, 2020

\begin{abstract}
The study aims to describe yoga asanas and increased the mental attitude of South African adolescents. In this modern era of society life, many studies have been conducted on health such as fitness, aerobics, etc. If further examined, sport is only healthy the body parts or physical exterior, and the exercise has a little effect on human mental and spiritual health. Therefore, one of the ways that can be taken to increase the physical and mental health of humans is by carrying out the teachings of Yoga. Yoga offers a simple and practical solution to balance between physical and mental human, because mental and spiritual in Yoga can help humans interact more effectively, there are various kinds of obstacles that humans face in their daily lives. In this case, yoga is expected to help a person in awakening inner strength, cleanliness and excitement, and teaches physical and mental self-control exercises to achieve the final goal called Samadhi.
\end{abstract}

Keywords: Yoga Asanas; Mental Attitude; Adolescents

\section{INTRODUCTION}

The purity of the heart is a source that will achieve budi dharma and moksha (liberation). By praying and worshiping God for His blessing, He will determine His people to reach perfection. Only by devoting to God, it can make people become virtuous human and have a good moral. To cause a sense of devotion to God in the form of abstract, it is necessary to have faith first. If we say we do not have faith in God, how can people devotee to Him. Therefore, it is necessary to have a firm belief in every people.

If seen from the goal of every Hindu to reach Moksha and Jagathita, it can be assumed that humans will not be able to reach 
Moksha if it is still covered by the laws of Karma and Punarbawa. The only way to reach Moksha is to do a kidness, hence humans must be in a state of physically and mentally healthy, a person will not be able to do anything if his body is not healthy. Therefore, one way according to the Hindu concept that can be taken is to do Yoga both meditation and asanas. Besides that according to Streeter, Chris C., et al. (2007), understanding the relationship betweenbehavior and neurochemistry would be an important step inunderstanding how the practice of yoga exerts its beneficialeffects.

Asanas are postures or positions of the body that can master the mind and do not need to force the body. Ananta samapattibhyam is a Yoga practitioner must take asanas movements according to the state of his body, Tato Dvandva Anabhighatag means that a Yoga practitioner must be free from environmental influences to be able to survive in heat, cold, sick and happy, bright and dark, sweet and bitter, luxurious and simple. Yoga has been applied in the field of therapeutics in modern times. Studies have been conducted to understand changes occurring during Yogic exercises (asanas and pranayamas). Significant physical, physiological, psychological and endocrinal changes have been reported by following various Yogicregimes over a period of time (Patel, \& North, 1975) (Rugmini, \& Sinha, 1976).

Humans are said to be healthy if they are physically, mentally, and spiritually healthy. What is meant by physical health is people can be avoided from various kinds of physical illnesses such as minor illness (flu) to chronic diseases (cancer). Mental health is the ability to adjust oneself, with other people and society, and the environment in which humans live, while spiritual health is spiritually healthy that supported by physical and mental health. In maintaining the health of these three groups, it is necessary to do a routine exercise or practice not just a theory. Hatha Yoga has become increasingly popular in western countries as a method for coping with stress and as a means of exercise and fitness training (Bal, \& Kaur, 2009).
In this modern era of society life, many studies have been conducted on health such as fitness, aerobics, etc. Yoga provides one of the best means of self-improvement and gaining full potential of one's body, mind \& soul.It has been proved beyond doubt that pranayama and certain asanas area very important means for preventing and curing many ailments. Over the last 10 years, research studies have shownthat the practice of Yoga improves strength and flexibility and may help in control parameters as blood pressure, respiration and heart rate, and metabolic rates (Tundwala, Gupta, Kumar, Singh, Sandeep, Dayal, \& Prakash, 2012).

If further examined, sport is only healthy the body parts or physical exterior, and the exercise has a little effect on human mental and spiritual health. Therefore, one of the ways that can be taken to increase the physical and mental health of humans is by carrying out the teachings of Yoga. Yoga offers a simple and practical solution to balance between physical and mental human, because mental and spiritual in Yoga can help humans interact more effectively, there are various kinds of obstacles that humans face in their daily lives. In this case, yoga is expected to help a person in awakening inner strength, cleanliness and excitement, and teaches physical and mental self-control exercises to achieve the final goal called Samadhi.

\section{METHODS}

This study used qualitative research, in which research that used data verbally and theoretical qualifications and in testing hypotheses not processed through mathematical calculations with various statistical formulas, data processing were carried out using certain thought patterns according to logic. Data collection techniques used in this study were (1) observation, (2) interviews, (3) literature study.

The steps of data analysis carried out in this study were (a) providing editing and coding data on the data collected in the field based on the classification that has been made; (b) classifying the data that has been collected based on the codes provided hence 
there is a data grouping; (c) re-examine the completeness collected in each group and then consider the further steps required: require to re-variation, complete it with other data sources or steps; (d) required by analyzing, synthesizing, interpreting, explaining, and then concluding; (e) reduce and classify data to see the tendencies; (f) conclude the results of the study after first verifying the data deemed necessary and supporting the conclusion process through cross-checking between the two data obtained by other methods (data triangulation).

\section{RESULTS AND DISCUSSIONS}

All forms and teachings of yoga are not the teachings which theoretical discussion, but the teachings of yoga contain the conceptual value (theory and practice). If the teaching is only read, memorized, or just remember, it will be in vain. Meanwhile, if the teachings of yoga are carried out regularly and continuously, you will get a sense of patience, diligence, and tenacity. Yoga is an interesting thing to discuss, because yoga is universal and quite popular among people both Hindus and other people. Yoga which is one part of sad darsana, is now studied by most of the world's population. Not only Hindus are interested in practicing yoga, but also many outsiders who are interested in practicing yoga (Sudarsana, 2019).

The high desire of South African adolescents to take part in the practice of yoga asanas is the main capital that comes from within a self. The desire to know yoga deeply, seeing yoga can be beneficial for the physical and spiritual, and to get peace of soul and patience is the foundation of South African adolescents in participating in the yoga asanas practice activities. These internal factors, if combined with external factors, especially the benefits of the yoga asanas movement, which has a very good effect on the body and systems in the body, can create humans who physical and spiritual health. Yoga, a vedic science has been applied in the field oftherapeutics in modern times. Yoga has given patients thehope to reduce medication besides slowing the progressionof the disease. Yoga employs stable postures or asanas andbreath control or pranayama (Singh, Malhotra, Singh, Madhu, \& Tandon, 2004).

Asanas practice regularly will have a good impact on physical health, in which later can encourage the physical and tissues and organs in the body to perform duties normally. Significant losses in health will be experienced if one of the organs or tissues does not function properly, thus it requires to do a rejuvenation of diseased body organs that can be repaired through yoga asanas practice. Muscles, bones, nerves, glands, respiratory systems, blood circulation are harmonized thus all of these tissue systems help one another. Digestive functions are stimulated hence the right amount of digestive sap (saliva, enzymes, etc.) flows. The entire organ system is brought into a balanced state so that the internal organs they control are neither too active nor less active.

Yoga asanas are a movement that different from other movements, slow, smooth which contains a deep respiratory system and deep relaxation for the physical and spiritual body. Yoga asanas can provide increased physiology through the pranayama stage by absorbing the energy content of life from nature or prana, thus making more prana content in the body that can refresh all the systems in the body.

Yoga asanas are very useful in rejuvenating and maintaining the spine and its glands to function properly. In the middle of the spine, there is a spinal cord composed of nerve tissue that produces two very strong hormones, namely adrenaline and noradrenaline. Both of these hormones tend to increase blood pressure. Most importantly, without an adrenaline doubt that accelerates the heartbeat, increases the level of oxygen consumed in the body, and accelerates the respiratory rate, regulates blood to limbs, reduces digestive function, makes sense organs such as eyes and ears more sensitive and many other things. These hormones also prepare the body to react or not, which can be the wisest course of action by making the 
body more aware and pushed externally (Satyananda, 2002).

Every yoga asanas movement that is interesting, pressing, and rotating in varying degrees, is actually a way to prevent and correct the wrong position of the spine in all positions, namely upright, sitting, and lying down. Yogis since ancient times realized the importance of perfect health, which comes from the spine. Maintaining the spine properly through the yoga asanas movement will be able to influence someone's attitude who does it because there is marrow in the spine that produces hormones that can affect human actions.

Besides, the practice of yoga asanas can also be beneficial for the endocrine glands which are very influential glands that far stretch on the operation of the whole body and mind. These glands are collectively known as glands without vessels. Endocrine glands do not have special vessels, but in the process of removing chemicals produced namely, the hormones are released directly with the bloodstream. Through this process, these hormones are distributed throughout the body and especially to the organs that respond to these hormones, which cause various changes in the activities of human organisms (Satyananda, 2002).

The hormones that result from the endocrine glands which streamed together with the bloodstream, will certainly stream through the entire body. With the circulation of these hormones in the body, there will be various changes in physical activity and mind which are a mental activity. This endocrine gland must be well maintained, so that it can produce quality hormones for the physical and mental activity or mind, thus later it can create good physical and mental activity or mind.

To assist the duties and functions of the endocrine glands, thus the bloodstreams that through blood vessels must be smooth without obstacles. Yoga asanas movement can help to rejuvenate blood vessels, by bending and stretching, thus the blood vessels become elastic and prevent them from hardening and blocking due to harmful toxins. Elastic blood vessels cause the correct pressure on the heartbeat and blood to stream stably. These stable bloodstreams will provide an even nutrition and oxygen supply throughout the body's tissues, thus making the body's tissues work perfectly.

Yoga asanas movement can prevent calcification, a condition in which hardening occurs in the periphery of blood vessels. Calcification can constrict blood vessel channels, thus the blood pressure becomes higher, which can cause high blood pressure (hypertension).

Besides these, following yoga-asanas many patients reported a feeling of wellbeing, more relaxed and satisfied, and a sense of relief from anxiety. They weremore alert and active which could be due to release of opiods and altered adreno-cortical activity. Yoga-asanas with its change in posture and controlled breathing inpranayama influences mental status of an individual allaying apprehension, stressand brings about feelings of well-being, and hormonal balance (Harinath et al., 2004; Udupa, Singh, Settiwar, 1975).

The thyroid gland is a small butterflyshaped gland located in front of the neck on each side of the throat. This gland produces thyroxine, a powerful hormone that affects almost every cell in the body. Its main function is to regulate the level of oxygen and food consumed in different types of cells in the body's metabolism. Among the others, this gland has a high dominant influence on metabolism, stimulates bone growth, increases the sensitivity of nerve tissue, regulates blood formation, helps protect the body from infection, and has an activating or stopping effect on other body organs. Thyroxine deficiency can cause metabolic processes in the body to be inhibited, causing humans to be lazy. In this case, yoga asanas can help to improve the workings of the thyroid gland and encourage it to produce the right amount of this main hormone (Satyananda, 2002).

Yoga asanas can maintain the physical and spiritual body at its best condition and encourage unhealthy bodies to become healthy. In the implementation of yoga asanas 
practice is not only instills education about yoga asanas, but it is accompanied by disciplined education applied in every yoga asanas movement. This discipline education will be able to educate adolescents to be more obedient in doing yoga asanas movements and minimize the occurrence of movement errors. Besides the discipline of movement, the discipline of time is also applied in the implementation of yoga asanas practice.

Besides, the atmosphere of intimacy and family is very much felt in the process of implementing the yoga asanas practice. This is due to the good interaction between South African adolescents and yoga asanas instructors. This good interaction causes South African adolescents to be more able to appreciate and respect fellow yoga participants and instructors. Indirectly, politeness behavior in South African adolescents has been formed.

The implementation of yoga asanas movement discipline and the utterance of prayer with great appreciation will be able to produce a harmony of yoga asanas movements carried out hence get good benefits for physical, physiological, and psychological health. Another benefit that can be generated is the occurrence of self-control in humans, both physically and spiritually. This self-control will be able to influence human attitudes in behaving as well as responding to stimuli from the outside environment and can foster and create a good, calm, and patient mentally hence can produce wise thoughts.

The practice of yoga asanas also has a positive impact on increased the spiritual qualities of South African adolescents. This is because, in the implementation of yoga asanas practice, the yoga asanas instructor gives enlightening words, especially when performing relaxation or savasana movements. This spiritual improvement will be able to affect the morale and mental quality of South African adolescents.

Increased the mental quality of South African adolescents has an impact on their personalities who become calmer in facing every situation, brave and confident in expressing opinions, able to speak in public.

Therefore based on the explanation above, it can be concluded that the practice of yoga asanas has an important role in increasing the mental attitude of South African adolescents. It is proved by the occurrence of the rejuvenation stage in the body organs such as blood tissue, respiratory system, endocrine glands, and goiter and the most vital is the rejuvenation of the spine. A healthy spine is a source of perfect health, which will affect the work of the human body system, in terms of increased the mental attitude. An increase in the spiritual part of South African adolescents affects the moral quality and mental attitude. South African adolescents become more patient, calm in facing any situation, brave and confident in expressing opinions, able to speak in public. Likewise in the mental attitude of South African adolescents who become polite, because of the education of mutual respect and respect among each other.

\section{CONCLUSION}

The implementation process of yoga asanas practice by South African adolescents, it begins with calming down and the mind through the Dhyana process. After doing Dhyana, proceed with saying Japa (prayer) as an introduction to God, so that while doing the practice can avoid negative things and still get His guidance. Nadi Sodhana is the next stage, which is the process of cleansing the pulse inside the human body. Then proceed to the stretching or pavanamuktasana stage, which functions to expel air or gas contained in the body and prevents a yogin from cramping or muscle spasms. The next stage is Surya Namaskara means respect for the Solar Deity, which consists of twelve kinds of movements. After doing the Surya Namaskara, then proceed by doing Asanas which means a state of the body that is steady, calm, relaxed, and comfortable both physically, mentally, and spiritually. Seen from the way of doing Asanas, it is divided into three types namely standing asanas, sitting asanas, and lying asanas. After doing the three types of asanas, 
proceed to the sequencing process which is the best way to end the very healthy asanas practice. This sequencing process functions to normalize the state of the muscles after doing yoga asanas. The pranayama process is the next stage that aims to gain peace of mind after doing the yoga asanas practice. Then proceed with the savasana stage, which in this posture, the body is at rest, completely motionless and replenished with prana energy.

\section{REFERENCES}

Bal, B. S., \& Kaur, P. J. (2009). Effects of selected asanas in hatha yoga on agility and flexibility level. J Sport Health Res, 1(2), 75-87.

Harinath, K., Malhotra, A.S., Pal, K., Prasad, R., Kumar, R., Kain, T.C., et al. (2004). Effects ofhatha Yoga and omkar meditation on cardio respiratory performance, psychological profileand melatonin secretion.Journal of Alternative and Complementary Medicine, 10, 261-268.

Patel, C., \& North, W. R. S. (1975). Randomised controlled trial of yoga and bio-feedback in management of hypertension. The Lancet, 306(7925), 93-95.

Rugmini, P. S., \& Sinha, R. N. (1976). The effect of yoga therapy in diabetes mellitus. Seminar on yoga. Man and Science, Delhi India, 175-189.
Streeter, C. C., Jensen, J. E., Perlmutter, R. M., Cabral, H. J., Tian, H., Terhune, D. B., ... \& Renshaw, P. F. (2007). Yoga Asana sessions increase brain GABA levels: a pilot study. The journal of alternative and complementary medicine, 13(4), 419-426.

Satyananda, S. (2002). Four Chapters on Freedom. Munger: Bihar School of Yoga.

Singh, S., Malhotra, V., Singh, K. P., Madhu, S. V., \& Tandon, O. P. (2004). Role of yoga in modifying certain cardiovascular functions in type 2 diabetic patients. JAPI, 52, 203-206.

Sudarsana, I. K. (2019). Developing Spiritual Behavior through Yoga Training. Vidyottama Sanatana: International Journal of Hindu Science and Religious Studies, 3(1), 24-30.

Tundwala, V., Gupta, R. P., Kumar, S., Singh, V. B., Sandeep, B. R., Dayal, P., \& Prakash, P. (2012). A study on effect of yoga and various asanas on obesity, hypertension and dyslipidemia. Int $J$ Basic Appl Med Sci, 2(1), 93-8.

Udupa, K.N., Singh, R.H., \& Settiwar, R.M. (1975). A Comparative study on the effect of some In-dividual Yoga practices in normal persons.Indian Journal of Medical Research, 63, 10661071 